\title{
Niosh Lifting Equation for Assessing Manual Material Handling Technique in a Warehouse Company
}

\author{
Amaya Flocerfida ${ }^{1}$, Argayoso Kimberly Clariz ${ }^{2}$, Tatlonghari Rachelle Ann ${ }^{2}$ \\ ${ }^{1}$ College of Engineering, University of Perpetual Help System Laguna, Biñan, Philippines \\ ${ }^{2}$ Industrial Engineering Department, University of Perpetual Help System Laguna, Biñan, Philippines
}

Email address:

amaya.flocerfida@uphsl.edu.ph (A. Flocerfida), Kimberly.argayoso@gmail.com (A. K. Clariz)

\section{To cite this article:}

Amaya Flocerfida, Argayoso Kimberly Clariz, Tatlonghari Rachelle Ann. Niosh Lifting Equation for Assessing Manual Material Handling Technique in a Warehouse Company. International Journal of Engineering Management. Vol. 3, No. 2, 2019, pp. 40-45.

doi: $10.11648 /$ j.ijem.20190302.11

Received: June 10, 2019; Accepted: July 11, 2019; Published: August 8, 2019

\begin{abstract}
Every warehouse company must protect their employees from possible health risks especially the loaders or carriers to avoid work related musculoskeletal disorders. This research aimed to determine the factors that affect the safety of carriers or loaders inside a certain warehouse. Proper lifting techniques were studied to provide safer methods compared to current worker's execution or method. The primary data were obtained from the respondents through observations, interviews, and survey questionnaires such as Nordic Questionnaire. Time and motion study was used to determine how safety affects the time of each worker in finishing the job. To assess safety, NIOSH lifting equation is used, an ergonomic tool that equates to the required weight limit and lifting index of the loaders or carriers that execute manual material handling. The results of the study showed that all the respondents had high lifting index based on the pre-assessment test of NIOSH lifting equation which means that they are at high risk. After implementation of proper lifting techniques, post-assessment test showed that the respondents had yielded lower lifting index. The findings revealed that aging and length of stay in the warehouse are factors highly affecting workers' capacity of lifting and safety. Older workers are more at risk than younger ones when it comes to physical activities. The longer the exposure in lifting and carrying, the more risks it is for the body. A safety procedure guideline was developed and recommended to the company to avoid health issues or musculoskeletal disorders among loaders and carriers inside the warehouse.
\end{abstract}

Keywords: Work Related Musculoskeletal Disorders, NIOSH Lifting Equation, Lifting Index

\section{Introduction}

Manual Material Handling or MMH is one of the most difficult tasks for the workers and one of the most physically demanding work because of repetitive movements, awkward postures, forceful exertion etc. It is the main cause of work-related musculoskeletal disorder [1]. MMH is the leading source of injuries in the workplace between $24 \%$ and $35 \%$ [2]. The work environment can be the main reason why workers have health problems.

Different kinds of MSDs must be assessed to determine the appropriate ergonomic tool to be used. The NIOSH or the National Institute of Occupational Safety and Health developed a technique to reduce the effects of lower back pain (LBP) and work-related musculoskeletal disorders (WSMD).
This indicates the work practices guide for manual lifting [3]. To assess the factors that affect the efficiency of the workers in a certain warehouse in the Philippines, the NIOSH Lifting Equation was used.

Musculoskeletal Disorders are due to manual material handling practiced by warehouse carriers or loaders. The risks were mostly caused by non-ergonomically way of material handling. It can affect the workers' safety and pose health risks. The demographic profile of the workers such as age, height, and number of years in their current position were determined as well as the current method being used by the carriers or loaders in the liquor section of a warehouse. Relationship between the demographic profile of the workers 
and their safety in the workplace was also determined. Pre-assessment and Post Assessment using NIOSH was evaluated to determine the best safety procedure guidelines for recommendation to the company.

\section{Materials and Methods}

For attainment of the objectives of the study, a descriptive method of research with primary data gathered from the respondents through the use of observations and interviews among the population of the study. A process chart was used as a representation of the sequence of steps, work flows, working processes, systems and procedure. It served as a tool for examining the process in detail to identify areas of possible improvement. Time and Motion Study was used to measure the time necessary for a job or task to be completed using the best method. This tool helped the team to evaluate if there is an improvement with the pre-assessment and post-assessment of the study. NIOSH lifting equation used worksheet to collect data from the respondents.

Since the data collected may be discrete and contain actual numbers, descriptive statistics were used. Pearson R Correlation was used on this study to determine the relationship of level of awareness of proper manual material handling and level of implementation safety procedure. The formula is stated below:

$$
r=\frac{n \Sigma x y-(\Sigma x)(\Sigma y)}{\sqrt{\left.\left[n\left(\Sigma x^{2}\right)\right]-(\Sigma x)^{2}\right] \sqrt{ }\left[n\left(\Sigma y^{2}\right)-(\Sigma y)^{2}\right]}}
$$

To test the significance of r, T- test was used,

$$
\mathrm{t}=\sqrt{\frac{\mathrm{r}(\mathrm{n}-2)}{\left(1-\mathrm{r}^{2}\right)}}
$$

\section{Results and Discussion}

\subsection{Demographic Profile of the Respondents}

Table 1. Profile of the respondents in terms of age.

\begin{tabular}{llll}
\hline Age & Frequency & Percentage & Rank \\
\hline $26-31$ & 6 & 40 & 1 \\
$32-37$ & 2 & 13.3 & 4 \\
$38-43$ & 4 & 26.7 & 2 \\
$44-49$ & 3 & 20 & 3 \\
Total & 15 & 100 & \\
\hline
\end{tabular}

As shown in the table regarding the age composition of the respondents, 6 out of 15 respondents (40\%) are 26-31 years old, 4 or $26.7 \%$ are $38-43$ years old, 3 or $20 \%$ are $44-49$ years old and 2 or $13.3 \%$ are $32-37$ years old.

Age should be considered since it is known that muscular strength declines from middle age onwards [4]. Middle-aged people are particularly prone to low-back problems owning to the instability of their lumbar motion segments. Aging process leads to a decrease in muscle mass and strength. Loss of strength is directly connected with reduction of muscle mass. The muscular system accounts approximately $40 \%$ of the total body mass and human body's cell mass consists in $75 \%$ of muscle cells [5].

Table 2. Profile of the respondents in terms of height.

\begin{tabular}{llll}
\hline Height $(\mathbf{c m})$ & Frequency & Percentage & Rank \\
\hline $154.94-162.08$ & 3 & 20 & 2.5 \\
$162.09-166.23$ & 6 & 40 & 1 \\
$166.24-170.38$ & 3 & 20 & 2.5 \\
$170.39-174.53$ & 2 & 13.3 & 4 \\
$174.54-178.68$ & 1 & 6.7 & 5 \\
Total & 15 & $100 \%$ & \\
\hline
\end{tabular}

The above table above shows the height of the respondents in which 6 out of $15(40 \%)$ stand $162.09-166.23 \mathrm{~cm}, 3$ or $20 \%$ stand $166.24-170.38 \mathrm{~cm}, 3$ or $20 \%$ stand $154.94-162.08 \mathrm{~cm}, 2$ or $13.3 \%$ stand $170.39-174.53 \mathrm{~cm}$, and 1 or $6.7 \%$ stand $174.54-178.68 \mathrm{~cm}$.

Shorter people are less likely to have lower back pain or break a hip [6]. One possible reason taller people have a bigger chance of a hip fracture is their high center of gravity. That not only makes them more likely to fall, but it also may make them hit the ground with more force if they do.

Table 3. Profile of the respondents in terms of number of months in the current position.

\begin{tabular}{llll}
\hline Months in the current position & Frequency & Percentage & Rank \\
\hline $68-91$ & 6 & 40 & 1 \\
$92-115$ & 4 & 26.7 & 2 \\
$116-139$ & 1 & 6.7 & 5 \\
$140-163$ & 2 & 13.3 & 3.5 \\
$164-187$ & 2 & 13.3 & 3.5 \\
Total & 15 & 100 & \\
\hline
\end{tabular}

The table above shows the number of months in the current position. Mostly or 6 out of 15 respondents $(40 \%)$ are in their current position for $68-91$ months, 4 or $26.7 \%$ for $92-115$ months, 2 or $13.3 \%$ for $140-163$ months, 2 or $13.3 \%$ for 164-187 months, 1 or and $6.7 \%$ for $116-139$ months.

\subsection{The Current Method of the Carriers or Loaders}

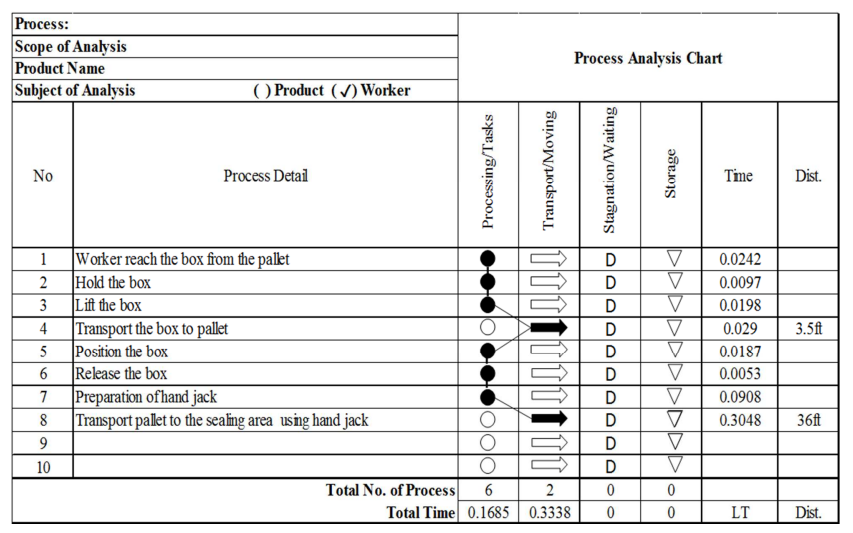

Figure 1. Process Chart.

The effects of combining the activities of lifting, lowering, pushing, pulling, and carrying into one work task; the resulting acceptable loads limits were quite different for the separate tasks compared with several of their combinations [7]. Manual handling at work includes lifting, putting down, 
carrying or moving, pushing or pulling of loads by one or more workers during the larger part of the work shift. Despite current technological advancements manual handling occurs in almost all working environments, workers are exposed to the risk of carrying or moving heavy loads for at least a quarter of their working time.

\begin{tabular}{|c|c|c|c|c|c|c|}
\hline No. & Left-Hand Description & Therblig & \multicolumn{2}{|c|}{ Symbol } & Therblig & Right-Hand Description \\
\hline 1 & & & & 0 & $\mathrm{TE}$ & Transport Empty \\
\hline 2 & & & & 0 & $\mathrm{G}$ & Grasp \\
\hline 3 & & & & 0 & $\mathrm{P}$ & Position \\
\hline 4 & Transport Empty & TE & 9 & & & \\
\hline 5 & Grasp & $\mathrm{G}$ & 0 & & & \\
\hline 6 & Position & $\mathrm{P}$ & 0 & & & \\
\hline 7 & Hold & $\mathrm{H}$ & 0 & 0 & $\mathrm{H}$ & Hold \\
\hline 8 & Transport Loaded & $\mathrm{TL}$ & 0 & 0 & $\mathrm{TL}$ & Transport Loaded \\
\hline 9 & Pre-position & $\mathrm{PP}$ & 0 & 0 & PP & Pre-position \\
\hline 10 & \begin{tabular}{|l|} 
Release Load \\
\end{tabular} & $\mathrm{RL}$ & 0 & 0 & $\mathrm{RL}$ & Release Load \\
\hline 11 & Transport Empty & $\mathrm{TE}$ & 0 & 0 & TE & Transport Empty \\
\hline
\end{tabular}

Figure 2. Therbligs Process Chart.

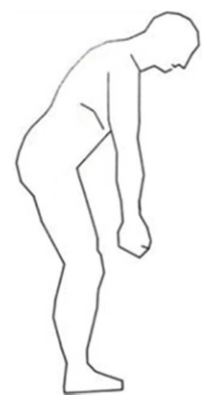

Figure 3. Current Execution.

The carriers or loaders manually lifted the box by bending his back to reach the box, grasp it with both of his hands then lift the box by straightening or lifting his box towards his body. Basically, the carriers or loader used his back to lift box not his feet and lift the box with their own way or strategy as fast as possible to finish their work. The abdominal and thoracic muscles play a major role in stabilising the spine when a weight is lifted. When a person leans forward to lift a weight, a moment of flexion is placed on the spine [8]. The heavier the weight, the greater the flexion strain.

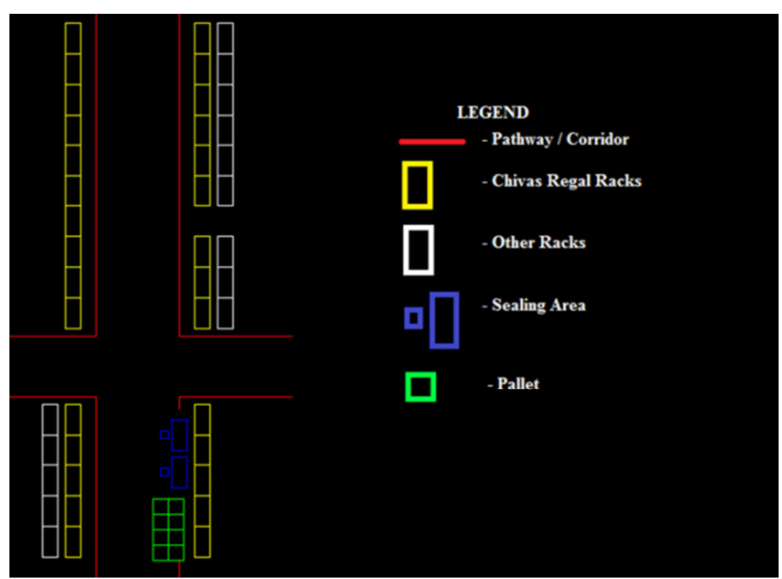

Figure 4. Floor Plan of Liquor section - warehouse.

\subsection{The Result of Pre-Assessment (NIOSH) and Post-Assessment (NIOSH)}

\subsubsection{The Result of Pre-Assessment (NIOSH)}

Table 4. Results of respondents' required weight limit pre-assessment.

\begin{tabular}{llll}
\hline Required Weight Limit (lb.) & Frequency & Percentage & Rank \\
\hline $10.9-11.92$ & 1 & 6.67 & 5 \\
$11.93-12.95$ & 3 & 20 & 3 \\
$12.96-13.98$ & 5 & 33.33 & 1 \\
$13.99-15.01$ & 3 & 20 & 3 \\
$15.02-16.04$ & 3 & 20 & 3 \\
Total & 15 & 100 & \\
\hline
\end{tabular}

It is shown in the table the results of respondents' required weight limit from NIOSH lifting equation. Five out of 15 or $33.3 \%$ answered 12.96-13.98 lbs., 3 or $20 \%$ answered 11.93-12.95 lbs., 3 or $20 \%$ answered $13.99-15.01 \mathrm{lbs}$., 3 or $20 \%$ answered 15.02-16.04 lbs., and 1 or $6.67 \%$ answered 10.9-11.92 lbs.. Therefore, there was a high risk to the respondents.

The primary product of the NIOSH lifting equation is the Recommended Weight Limit (RWL), which defines the maximum acceptable weight (load) that nearly all healthy employees could lift over the course of an 8 hour shift without increasing the risk of musculoskeletal disorders (MSD) to the lower back [9]. For risk assessment, the recommended loads heavier than $25 \mathrm{~kg}$ are always to be considered a risk for Lower back pain while less than $3 \mathrm{~kg}$ do not pose a risk. For loads between $3-25 \mathrm{~kg}$, risk assessment shall be performed using the National Institute for Occupational Safety and Health (NIOSH) lifting equation. [10]

Table 5. Results of respondents' lifting Index pre-assessment.

\begin{tabular}{llll}
\hline Lifting Index & Frequency & Percentage & Rank \\
\hline $2.73-2.99$ & 5 & 33.33 & 1 \\
$3.00-3.26$ & 4 & 26.67 & 2.5 \\
$3.27-3.53$ & 4 & 26.67 & 2.5 \\
$3.54-3.80$ & 1 & 6.67 & 4.5 \\
$3.81-4.07$ & 1 & 6.67 & 4.5 \\
Total & 15 & 100 & \\
\hline
\end{tabular}

It is shown in the table the results of respondents' required lifting index from NIOSH lifting equation. Five or 33.3\% got $2.73-2.99,4$ or $26.67 \%$ got $3-3.26,4$ or $26.67 \%$ got $3.27-3.53$, 1 or $6.67 \%$ got $3.54-3.8$, and 1 or $6.67 \%$ got $3.54-3.81$. Therefore, there was a high risk to all the respondents.

A Lifting Index (LI) is calculated to provide a relative estimate of the level of physical stress and MSD risk associated with the manual lifting tasks evaluated.

Table 6. Results of evaluated respondents' lifting Index pre-assessment.

\begin{tabular}{llll}
\hline Lifting Index & Frequency & Percentage & Rank \\
\hline LI $<1.0$ - Normal risk to employee & 0 & 0 & 2 \\
LI $>1.0$ High risk to employee & 15 & 100 & 1 \\
Total & 15 & $100 \%$ & \\
\hline
\end{tabular}

It is shown in the table the results of evaluated respondents' 
Lifting Index. The result LI $>1.0$ revealed that 15 out of 15 respondents $(100 \%)$ are at High Risk and 0 or $0 \% \mathrm{LI}<1.0$ for Normal risk to employee.

A Lifting Index value of less than 1.0 indicates a nominal risk to healthy employees. A Lifting Index of 1.0 or more denotes that the task is high risk for some fraction of the population [11]. As the LI increases, the level of low back injury risk increases correspondingly. Therefore, the goal is to design all lifting jobs to accomplish a LI of less than 1.0.

\subsubsection{The Result of Post-Assessment (NIOSH)}

Table 7. Results of respondents' required weight limit post-assessment.

\begin{tabular}{llll}
\hline Required Weight Limit & Frequency & Percentage & Rank \\
\hline $40.61-42.11$ & 1 & 6.67 & 4.5 \\
$42.12-43.62$ & 2 & 13.33 & 3 \\
$43.63-45.13$ & 7 & 46.67 & 1 \\
$45.14-46.64$ & 4 & 26.67 & 2 \\
$46.65-48.15$ & 1 & 6.67 & 4.5 \\
Total & 15 & 100 & \\
\hline
\end{tabular}

It is shown in the table the results of respondents' required weight limit from NIOSH lifting equation. Out of 15 respondents, 7 or $46.67 \%$ ) have $43.63-45.13 \mathrm{lbs}$. required weight limit, 4 or $26.67 \%$ have $45.14-46.64 \mathrm{lbs}$., 2 or $13.33 \%$ have $42.12-43.62 \mathrm{lbs} ., 1$ or have $40.61-42.11 \mathrm{lbs} ., 1$ or $6.67 \%$ have $46.65-48.15 \mathrm{lbs}$.. Therefore, there was a normal risk to all employees.

The primary product of the NIOSH lifting equation is the Recommended Weight Limit (RWL), which defines the maximum acceptable weight (load) that nearly all healthy employees could lift over the course of an 8 hour shift without increasing the risk of musculoskeletal disorders (MSD) to the lower back [12]. For risk assessment, the recommended loads heavier than $25 \mathrm{~kg}$ always are to be considered a risk for Lower back pain while less than $3 \mathrm{~kg}$ do not pose a risk. For loads between 3-25 kg, risk assessment shall be performed using the National Institute for Occupational Safety and Health (NIOSH) lifting equation [13].

Table 8. Results of respondents' lifting Index.

\begin{tabular}{llll}
\hline Lifting Index & Frequency & Percentage & Rank \\
\hline $0.91-0.94$ & 3 & 20 & 3 \\
$0.95-0.98$ & 5 & 33.33 & 2 \\
$0.99-1.02$ & 7 & 46.67 & 1 \\
Total & 15 & 100 & \\
\hline
\end{tabular}

It is shown in the table the results of respondents' required lifting index from NIOSH lifting equation. Seven or $46.67 \%$ obtained $0.99-1.02,5$ or $33.33 \%$ obtained $0.95-0.98$, and 3 or $20 \%$ obtained $0.91-0.94$. Therefore, there was a normal risk to all employees.

A Lifting Index (LI) is calculated to provide a relative estimate of the level of physical stress and MSD risk associated with the manual lifting tasks evaluated [14].

It is shown in the table the results of evaluated respondents' Lifting Index with $(100 \%) \mathrm{LI}<1.0$ - Normal risk to employee is 15 out of 15 respondents and $(0 \%) \mathrm{LI}>1.0$ High risk to employee is 0 .

A Lifting Index value of less than 1.0 indicates a nominal risk to healthy employees. A Lifting Index of 1.0 or more denotes that the task is high risk for some fraction of the population. As the LI increases, the level of low back injury risk increases correspondingly. Therefore, the goal is to design all lifting jobs to accomplish a LI of less than 1.0.

Table 9. Results of evaluated respondents' lifting Index post-assessment.

\begin{tabular}{llll}
\hline Lifting Index & Frequency & Percentage & Rank \\
\hline LI $<1.0$ - Normal risk to employee & 15 & 100 & 1 \\
LI $>1.0$ High risk to employee & 0 & 0 & 2 \\
Total & 15 & 100 & \\
\hline
\end{tabular}

Secondly, the supporting tools are the Nordic Standard questionnaire and the time study. The results of the Nordic Standard questionnaire revealed that the most hurt part of the respondent's body are the lower back, upper back, shoulders, and arms. The percentage of answering yes in pain are: Neck $33 \%$, Shoulders $87 \%$, Arms 87\%, Wrists/Hands 73\%, Upper Back 87\%, Lower Back 93\%, Hips/Thighs 67\%, Knees 53\%, and Ankles/Feet 33\%. This also shows that most of them did not seek medical help or attention for their felt pain and only 1 out of 14 of the respondents has consulted a physician.

The Time Study covers the time of each worker to transfer boxes from rack to pallet with given 5 trials. The pre-assessment with their current lifting technique and the post-assessment with the researchers' recommended lifting techniques. As shown on the two results, the average of each worker to do the task only has small difference in time. Pre-assessment has an average of 5.5572 seconds and the Post-assessment has an average of 5.355867. Most of the workers show a lower time average with the post-assessment using the researchers' lifting techniques.

\subsection{The Relationship Between Demographic Profile and Safety of the Carriers or Loaders}

Table 10. Gathered Data for Demographic Profile and Safety.

\begin{tabular}{lllll}
\hline Worker & Age & Height & Length of stay & Lifting Index \\
\hline 1 & 26 & 170.31 & 73 & 2.735 \\
2 & 28 & 162.08 & 75 & 2.738 \\
3 & 28 & 170.35 & 80 & 2.740 \\
4 & 29 & 162.44 & 79 & 2.807 \\
5 & 30 & 168.23 & 82 & 2.939 \\
6 & 31 & 178.68 & 90 & 3.002 \\
7 & 32 & 166.55 & 93 & 3.109 \\
8 & 37 & 175.48 & 113 & 3.174 \\
9 & 38 & 158.36 & 95 & 3.200 \\
10 & 38 & 168.45 & 93 & 3.266 \\
11 & 41 & 170.26 & 135 & 3.323 \\
12 & 43 & 162.48 & 145 & 3.396 \\
13 & 44 & 166.29 & 163 & 3.397 \\
14 & 46 & 154.29 & 165 & 3.560 \\
15 & 49 & 170.40 & 187 & 3.997 \\
\hline
\end{tabular}

It is shown in the table 10 the relationship of the 
demographic profile and safety of the respondents. The demographics came from the company and the data of safety came from the lifting index of the NIOSH lifting equation. It shows that all the data and information gathered by the researchers are diverse.

It is shown in Table 11 that the age and length of stay have a very strong positive relationship with safeness. Older workers are more at risk than younger ones when it comes to physical activities. The longer the exposure in lifting and carrying, the riskier it is for the body. The height and safety have a very weak negative relationship with safety that contradicts the findings of Ratini that shorter people are less likely to have lower back pain or break a hip. One possible reason taller people have a bigger chance of a hip fracture is their high center of gravity. That not only makes them more likely to fall, but it also may make them hit the ground with more force if they do.

Table 11. Relationship of Demographic Profile and Safety.

\begin{tabular}{llllll}
\hline Independent Variable (x) & Dependent Variable (y) & Pearson Value & Relationship & T-Value & T-Test Results $\boldsymbol{\alpha}=\mathbf{0 . 0 5}$ \\
\hline Age & & 0.9629 & Very Strong Positive & 12.86520825 & Significant \\
Height & Lifting Index & -0.1356 & Very Weak Negative & -0.49347061 & Not significant \\
Length of Stay & & 0.9258 & Very Strong Positive & 8.83041895 & Significant \\
\hline
\end{tabular}

\section{Conclusions}

In this paper, the ergonomic problems encountered in manual material handling in a warehouse was studied. It was found out all of the carriers or loaders employed in the liquor section of the warehouse are male. The height, age, and length of stay of the carriers or loaders in the company are diverse so the researchers used this data and information in assessment relating to their safety. It was also revealed that they are already exposed to stress and safety issue related on lifting loads. It can be noted that the current execution in manual material handling of the carriers or loaders is ergonomically incorrect which means they are more prone to work related musculoskeletal disorders. From the Pre-assessment of the NIOSH Lifting equation, all of the carriers' or loaders' lifting index are greater than 1 which indicates that they are at high risk meaning they are lifting the boxes above the recommended weight limit or with incorrect execution of lifting or carrying. As obtained from the Post-assessment of the NIOSH Lifting equation, all of the carriers' or loaders' lifting index are less than 1 that indicates they are at normal risk. It was also found out that the age and length of stay in the current position of the respondents' highly affect their safety. Aging can affect the ability of the workers to do manual material handling and other physical activities. Older workers are more at risk than younger ones when it comes to physical activities. The longer the exposure in lifting and carrying, the riskier it is for the body. Due to absence of company's Safety Procedure Guidelines, the carriers or loaders of the warehouse have higher risk of developing Musculoskeletal Disorders that may cause long term health issues and lessen the workers' effectiveness at work.

Some corresponding recommendation can be made according to the above conclusions. For the profile variables of the workers that may affect carrier's or loader's safety at work, the weight and health conditions or medical history must be considered. To widen the scope of the study, other persons involved in manual material handling such as truck loaders should also be considered. Other ergonomic tools such as Manual Handling assessment charts as MAC too and WISHA lifting equation of revaluating manual material handling may also be used to compare results.

\section{References}

[1] Triyanti, D. (2017). Risk Assessment of Manual Material Handling. Materials Sciences and Engineering.

[2] A. Burciaga-Ortega and J Santos-Reyes. (2010). Manual Handling Operations Risk Assessment safety, Accident, and Reliability Analysis (SARACS). 189.

[3] Shahu, R. (2016). The NIOSH Lifting Equation for Manual Lifting and its Application. Journal of Ergonomics.

[4] A. Pinder, G. Frost and H. Hill. (2011). Prospectove Evaluation of the NIOSH Lifting Equation.

[5] K. Keller and M. Engelhardt2013Strength and muscle mass loss with aging process. Muscle, Ligaments and Tendons Journal 346-350.

[6] F. Elfeituri and S. Taboun. (2012). An Evaluation of the NIOSH Lifting Equation. International Journal of Occupational Safety and Ergonomics.

[7] P. Gidikova and G. Sandeva2016MANUAL HANDLING RISK ASSESSMENT AND MORBIDITY STRUCTURETrakia Journal of Sciences360-366.

[8] Middleworth, M (2011). Process benefits of Ergonomics in the Workplace. Ergonomics Plus Inc. march 21, http://ergopluc.com/workplace-ergonomics-benefits/.

[9] P. Kuijer, J. Verbeek, B. Visser, L. Elders, V. Roden, V. Wittenboer2012An Evidence-Based Multidisciplinary Practice Guideline to Reduce the Workload due to Lifting for Prevening Work-related Low Back PainNIOSH Lifting Equation.

[10] Baba Md Deros, D. D. (2015). A Study on Ergonomic Awareness among Workers Performing Manual Material Handling Activities.

[11] H. Mohammadia, M. Motamedzadeb, M. Faghiha, H. Bayat, M. Habibi and S. Musavi. (2015). Manual Material Handling Assessment Among Workers. International Journal of Occupational Safety and Ergonomics.

[12] M. Babu, M. Uthayakumar and K. Murugabhoopathy. (2014). International Journal of Innovative Research in Science, Engineering and Technology. Assessment on Ergonomics Risk during. 
[13] Health, N. I. (2012). National Institute for Occupational Safety and Health (NIOSH) Centers for Disease Control and Prevention. California Department of Industrial Relations.
[14] R. Gandhi. (2016). Manual Material Handling: A classification Scheme. Science Direct, 568-575.

\section{Biography}

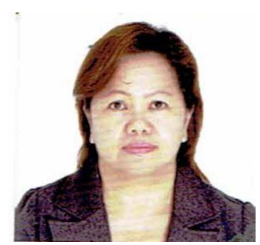

Flocerfida is the Dean of the College of Engineering in University of Perpetual Help System Laguna. She actively participates as one of the CHED's Assessor for Quality Assurance of Higher Educational Institution's Vertical Typology and Institutional Sustainability Assessment, and a member of Regional Quality Assessment Team for Engineering Education. She was conferred as an ASEAN Engineer and awarded as 2017 Outstanding Chemical Engineer. She is also one of the Accreditors of Philippine Association of Colleges and Universities-Commission on Accreditation. She is also a Consultant for Environmental Management of Laguna International Industrial Park, Inc.

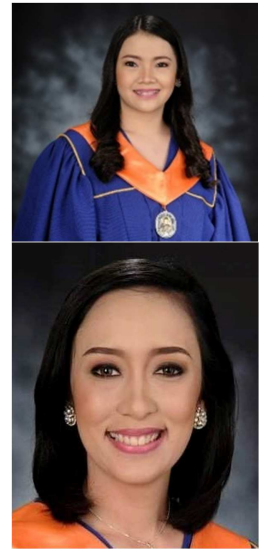

Argayoso Kimberly Clariz is a graduate of Bachelor of Science in Industrial Engineering at University of Perpetual Help System Laguna. She has special skills in drawing and layout applications using AUTOCAD and knowledgeable in SAP. She is also a Certified Lean Six Sigma Yellow Belt.

Tatlonghari Rachelle Ann is a graduate of Bachelor of Science in Industrial Engineering at University of Perpetual Help System Laguna. She is proficient in Microsoft Office such as Word, Excel, Powerpoint, SAP and Certified Lean Six Sigma Yellow Belt. 